\title{
Chemical Anthropomorphism: Acting Out General Chemistry Concepts in Social Media Videos Facilitates Student-Centered Learning and Public Engagement
}

Matthew O. Hight,1,2 Nhien Q. Nguyen,1,2 Timothy A. Su ${ }^{1, *}$

$5 \quad{ }^{1}$ Department of Chemistry, University of California, Riverside, CA 92507 United States

\section{ABSTRACT}

This Article describes the educational and public engagement outcomes of an activity called the "ChemClout Challenge" that was implemented in a general chemistry course at UC Riverside. Students worked in groups to make chemistry-themed videos, posted them to social media platforms, then voted on their favorite videos. The majority of students elected to make videos where they anthropomorphized general chemistry concepts, physically acting out principles such as ideal gas law relationships and electrolyte solubility. Students reported enjoying these anthropomorphized videos most. These types of videos received over one million views worldwide within the first month of posting on the social media platform, TikTok. After the course was over, 75 students completed voluntary Likert scale surveys to assess the educational and outreach impact of the ChemClout Challenge. $88 \%$ of students reported that the activity made chemistry more relatable, whereas $76 \%$ of students noted that the activity helped them retain course concepts two months after the course was completed, indicating the activity benefitted student learning. Moreover, $84 \%$ of students reported that their friends and family members outside of UC Riverside watched the videos, with $72 \%$ of students reporting that they explained the chemical concepts of their videos to their friends. These studies indicate that student-created social media videos that anthropomorphize chemistry are highly effective vectors for student-centered learning and public engagement in chemical concepts. This activity may find particular utility for educators during the COVID-19 pandemic, as it is compatible with distance learning. 


\section{GRAPHICAL ABSTRACT}

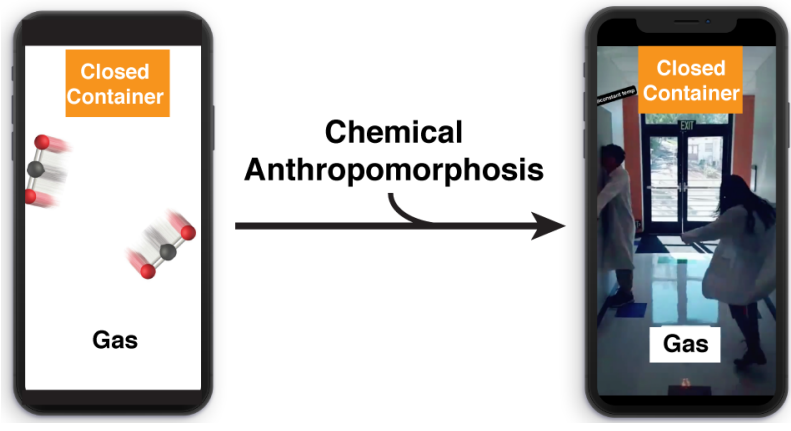

\section{KEYWORDS}

First-Year Undergraduate/General, High School/Introductory Chemistry, General Public, Public Understanding/Outreach, Collaborative/Cooperative Learning, Communication, Distance Learning, Internet/Web-Based Learning, Multimedia-Based Learning, Student-Centered Learning.

\section{INTRODUCTION}

The global 16-24 age group spends an average of 3 hours per day using social media apps. ${ }^{1}$ By the time students arrive onto college campuses for introductory science courses, many of them are already sophisticated creators and consumers of social media content. The advent of social media has thus presented instructors with new avenues for engaging students in their course material.2,3 Educators can make abstract course concepts more relatable for students by introducing these concepts through the familiar lens and formats of the digital communication apps that have come to define how students interact with and perceive their world. ${ }^{4}$

Over the past decade, chemical educators have increasingly incorporated social media videos into their curriculum to facilitate student learning. ${ }^{5}$ While instructor-created videos provide educators with greater control over what content is disseminated and how it is presented, student-created videos offer students agency in the active learning process. In creating chemistry-themed social media videos, students learn how to communicate chemical concepts in a clear and compelling fashion, with these concepts often becoming ingrained into their memory. ${ }^{6}$ Videos posted to public social media platforms have the additional benefit of engaging and teaching broad online audiences about chemical concepts.

Early adopters of social media in the chemistry classroom primarily utilized YouTube as a vehicle for students to make or watch videos that explain chemical concepts, real-world phenomena using chemical principles, ${ }^{6-9}$ lab techniques and lab experiments, ${ }^{10-14}$ and even music videos with chemistry- 
themed lyrics. ${ }^{15,16}$ Newer social media apps such Instagram, Snapchat, and TikTok have been utilized to create study aids ${ }^{17,18}$ and case study activities ${ }^{19}$, and videos based on the academic research experience $^{20}$ or at-home experiments. ${ }^{21}$ In this Article, we find that videos based on chemical anthropomorphism-where students physically act out chemical principles, concepts, and behaviors-are particularly potent agents for both student-centered learning and public engagement of chemistry.

These findings emerged from the implementation of a social media-based extra credit activity in a general chemistry course at UC Riverside called the "ChemClout Challenge". Students were tasked with creating short, chemistry-themed videos that were $15-60$ seconds long and posting them to various social media platforms. These videos received over 1.1 million views worldwide. The key objective of the activity was to make chemical concepts more relatable by having students actively create and consume chemistry content in the familiar "language" of social media. Though students were given the freedom to pursue any video format of their choosing, they largely favored creating and watching videos where they acted out the behaviors and properties of molecules, following recent trends of viral anthropomorphized science videos on TikTok. ${ }^{22}$ In this article, we describe the activity details and discuss educational and public engagement outcomes as assessed by student surveys and viewership metrics.

\section{DETAILS OF THE CHEMCLOUT CHALLENGE}

The ChemClout Challenge was introduced in the second quarter of a 3-quarter general chemistry series at UC Riverside to a class size of 278 students. The main concepts covered in the course included aqueous solutions, redox reactions, thermochemistry, gas laws, colligative properties, entropy, thermodynamics, and kinetics. ${ }^{23}$ Students were introduced to the ChemClout extra credit activity on the first day of class (syllabus available in Supporting Information). The rationale for the activity was communicated to students, and students were shown examples of effective science communication videos where scientific concepts were accurately communicated in an entertaining fashion (e.g., videos from the@labshenanigans and @chemteacherphil accounts on TikTok). Students were also shown examples of videos that would not receive credit: in particular, videos that demonstrated minimal relevance or effort. 
Students were given the freedom to choose the video topic and format. Videos were submitted in groups of 1-3 students. Each student in the group received the same extra credit score. Credit was awarded to videos that were at least 15 seconds long and contained course-relevant content. Students were not required to physically appear in videos, though many elected to do so. Students were incentivized to post their videos to publicly accessible social media platforms, such as TikTok, Instagram, YouTube, Facebook, Reddit, and Twitter to deepen the social media reach of their videos. Extra points were awarded for posting their videos to more than one social media platform. Rather than posting the videos to a single course-associated account, students were asked to post the videos themselves. Some students posted videos from their personal accounts, while others chose to create anonymous public accounts for the express purpose of posting their ChemClout videos. This way, students had digital control and ownership over their videos, which was particularly important since many students chose to physically appear in their videos. Students posting from personal accounts created opportunities for their videos to tap into the social networks of their home communities.

Students were encouraged to apply eight specific hashtags to their videos for various purposes. Students were asked to include the \#ChemClout and \#UCRChem1BW20 hashtags, both of which were unused hashtags at the onset of the program. The \#ChemClout hashtag was intended to collate all ChemClout videos across chemistry courses, quarters of instruction, and to include videos from other users wanting to participate in the ChemClout Challenge (https://www.tiktok.com/tag/chemclout). The \#UCRChem1BW20 hashtag was used to collate videos submitted specifically in the Winter 2020 quarter of the CHEM1B course at UCR (https://www.tiktok.com/tag/ucrchem1bw20). These two hashtags enabled us to track engagement and the number of video views. The remaining six hashtags were used to generate broad public interest and viewership, including popular hashtags such as \#UCRiverside, \#science, \#sciencememes, \#chemistry, \#chemistrymemes, \#scicomm. In the case of TikTok, many students chose to include the \#fyp hashtag, which helped videos go viral by appearing on the "For $\underline{\text { You }}$ Page" that TikTok users browse to find new videos.

The majority of videos were submitted and posted online in the two weeks preceding the activity's deadline. After the deadline, the instructor and graduate teaching assistants selected the three videos that they felt were the best examples of effective scientific communication based on creativity, 
entertainment value, and chemical relevance. All students were shown the instructor-selected videos during lecture. After watching the contenders, students used the Poll Everywhere response system during class to vote for their favorite video made by their peers. The video receiving the most Poll Everywhere votes was selected as the winner, and its creators received the most extra credit points.

Two months after the conclusion of the course, students were asked to complete voluntary, anonymized surveys. 75 students completed the follow-up survey that was a mixture of Yes/No and Likert scale survey questions. This activity received non-human subjects research determination from the UC Riverside Institutional Review Board. All videos from this activity are publicly available from student-owned accounts at the following web link: https://www.tiktok.com/tag/ucrchem1bw20.

Table 1. Student responses to Likert scale questions related to their overall enjoyment of making and watching the ChemClout videos.

\begin{tabular}{rrrrrr} 
& $\begin{array}{c}\text { Strongly } \\
\text { Disagree }\end{array}$ & Disagree & Neutral & Agree & $\begin{array}{r}\text { Strongly } \\
\text { Agree }\end{array}$ \\
\hline a) I enjoyed making the ChemClout videos. & ${ }^{a}$ & 1 & 1 & 10 & 22 \\
b) I enjoyed watching the ChemClout videos. ${ }^{a}$ & 0 & 0 & 3 & 16 & 56
\end{tabular}

aStudent responses $(\mathrm{N}=75)$ to the questions with answer choices of strongly disagree, disagree, neutral, agree, or strongly agree.

\section{ACTIVITY OUTCOMES}

165 out of 278 students participated in the activity, representing $59 \%$ of the class. 71 videos were produced in total by these students. Overall, students enjoyed both making and watching the

ChemClout videos (Table 1). The chemistry topics that students covered were well-distributed across the major course modules (see Supplementary Note 1). Data analysis on viewership was performed two months following the conclusion of the course. At this point however, 13 of the videos had been taken down by the student creators. The following viewership metrics refer to the 58 videos that remained public at the time of analysis.

Table 2. Views Per Social Media Platform.

\begin{tabular}{|c|c|c|c|c|}
\hline & TikTok & YouTube & Instagram & Twitter \\
\hline Average $^{a}$ & 22,134 & 11 & 71 & 180 \\
\hline Median $a$ & 835 & 7 & 70 & 32 \\
\hline Totala & $1,084,552$ & 78 & 1,629 & 6,286 \\
\hline$\#$ of Entries $b$ & 48 & 7 & 23 & 35 \\
\hline $\begin{array}{l}\alpha \text { The average, } \\
\text { obtained follo } \\
\text { YouTube, Ins } \\
b \text { Some videos }\end{array}$ & $\begin{array}{l}\text { edian, and } \\
\text { ing publish } \\
\text { gram, and } \\
\text { ere posted }\end{array}$ & $\begin{array}{l}\text { total num } \\
\text { ng of their } \\
\text { witter as c } \\
\text { o multiple }\end{array}$ & $\begin{array}{l}\text { er of views } \\
\text { videos on Til } \\
\text { May } 12,20 \\
\text { social media }\end{array}$ & $\begin{array}{l}\text { udents } \\
\text { Tok, } \\
0 .\end{array}$ \\
\hline
\end{tabular}


Viewership across social media platforms

While there were no specific guidelines about which social media app students should use, most students elected to first create videos using the TikTok platform, then re-post these videos to other social media platforms such as YouTube, Reddit, Instagram, Twitter, and Facebook. This predilection towards TikTok may have originated from the example videos that were shown on the first day of class, as all videos shown were TikTok videos. In addition, TikTok is both exceedingly popular and highly amenable to content creation, as was elegantly summarized by Hayes et al recently. ${ }^{21}$ TikTok is unique in its brevity; its purpose is to entertain viewers through attention-grabbing video clips that are typically 15 seconds long. Because of this time constraint, students learn to communicate core chemical concepts in concise, digestible formats. 46\% of TikTok's American user base are 18-24 years old and many users are teenagers, suggesting that our general chemistry students were already fluent in the mechanics of TikTok. ${ }^{24}$ Many popular videos on TikTok follow common themes and formats, allowing students to easily embed chemical concepts within the familiar syntax of TikTok.

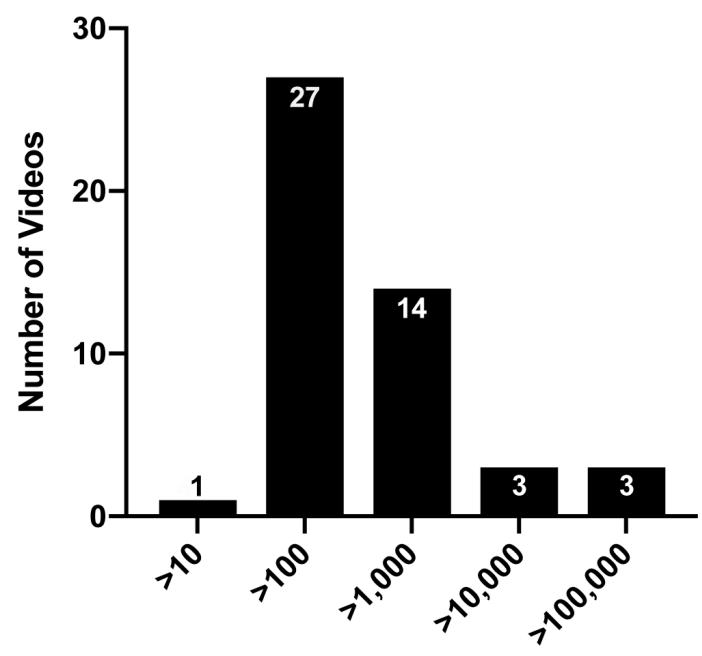

Number of Views

Figure 1. Distribution of video view counts posted on TikTok using the \#UCRChem1BW20 hashtag. Five videos received over 77,000 views.

At the time of analysis, 58 videos were posted by students across four primary social media platforms: TikTok, YouTube, Instagram, and Twitter (Table 2). TikTok viewership accounted for 1.08 million views, comprising $>99 \%$ of total ChemClout video views. The high viewership numbers are 
skewed by videos that went viral on TikTok. Five videos were viewed at least 77,000 times each, with the most watched video receiving 429,000 views (Figure 1). For the purposes of our discussion here, we refer to these 5 videos as the ones that went "viral". Notably, the videos that went viral on TikTok were also posted to Instagram and Twitter but received less than 50 views on the non-TikTok platforms. The median number of views per video on TikTok (835) were quite high compared to those on YouTube (7), Instagram (70), and Twitter (32), suggesting that TikTok is a particularly potent vehicle for delivering chemistry content.

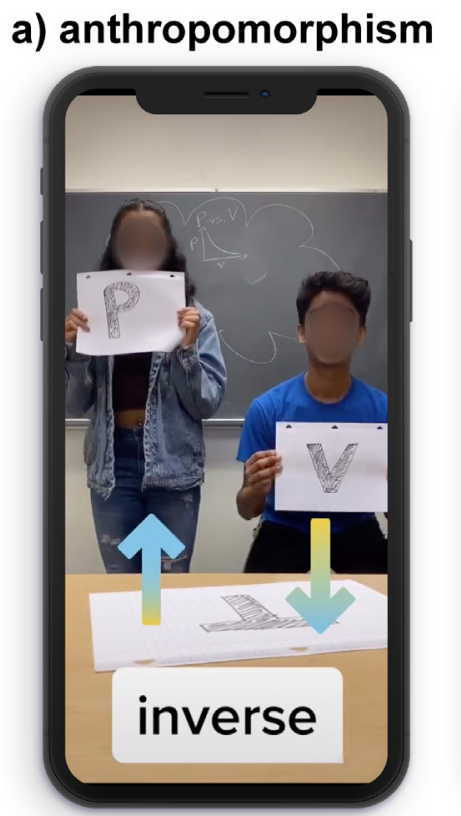

\section{Explaining chemical concepts via:}
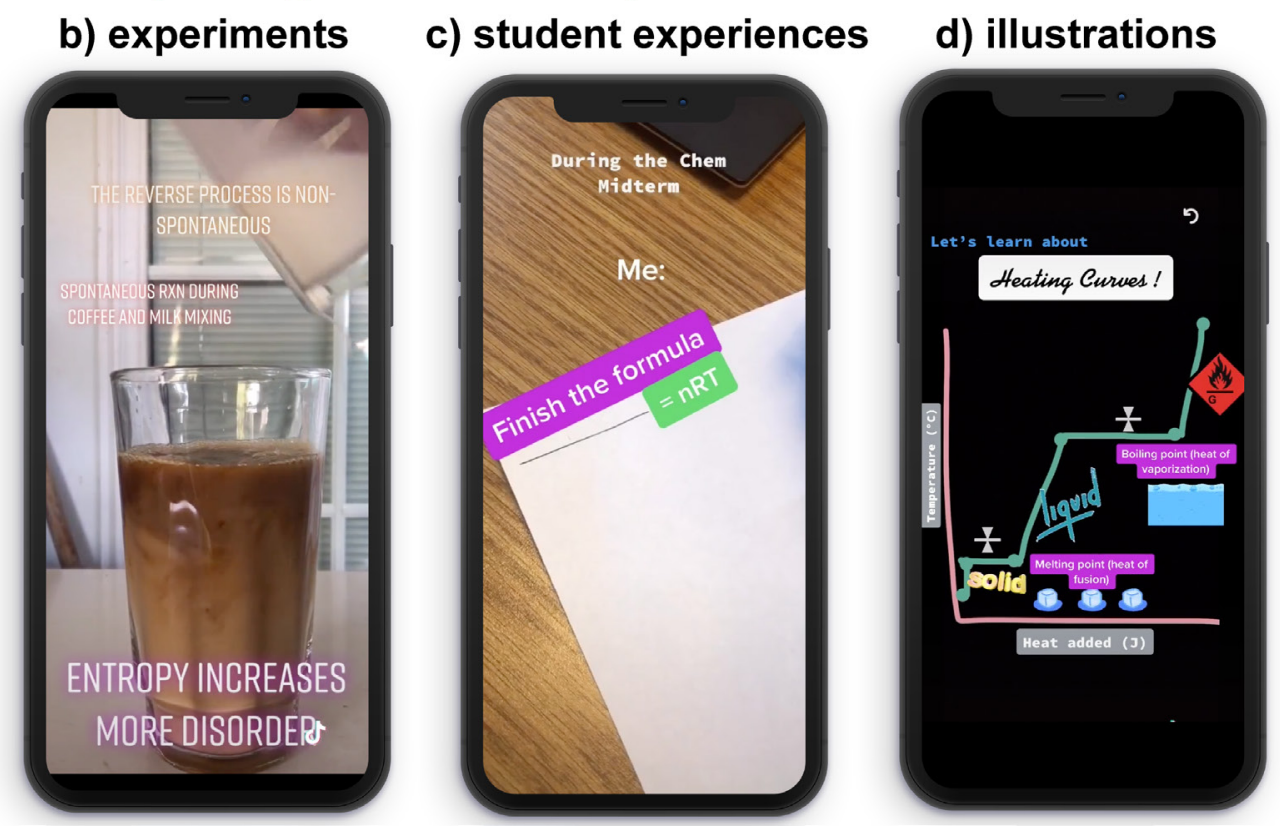

Figure 2. Representative still-shot images of the four major types of videos created by students. These videos are publicly accessible at https://www.tiktok.com/tag/ucrchem1bw20.

Preference for anthropomorphized chemistry videos

Student-created videos generally into four main categories: a) physically acting out chemical concepts, b) performing chemical experiments, c) describing the experiences of a chemistry student, and d) explaining chemical equations and concepts through animations or drawings. Figure 2 shows still-shot examples of each video type.

The majority of created videos $(71 \%)$ fell into the first category of anthropomorphized chemistry (Table 3). In the survey administered two months after the conclusion of the course, $85 \%$ of the 75 surveyed students indicated a preference for watching these videos where students acted out chemical 
concepts (Table 3). Beyond the student surveys, the anthropomorphized chemistry videos demonstrated wider appeal online. The 5 videos from the ChemClout Challenge that went viral on TikTok were based on the anthropomorphosis of chemical concepts, where students acted out chemical principles including the solubility of electrolytes vs. non-electrolytes, electronegativity principles, gas law relationships, polymerization, and ideal gas constants.

\begin{tabular}{|c|c|c|c|c|}
\hline & $\begin{array}{l}\text { Anthropo- } \\
\text { morphosis }\end{array}$ & $\begin{array}{r}\text { Home } \\
\text { Experiments }\end{array}$ & $\begin{array}{r}\text { Student } \\
\text { Experiences }\end{array}$ & $\begin{array}{r}\text { Animated } \\
\text { Explanations }\end{array}$ \\
\hline Average $^{a}$ & 30,057 & 664 & 8,167 & 863 \\
\hline Median $a$ & 873 & 585 & 4,576 & 267 \\
\hline Total $a$ & $1,051,997$ & 3,318 & 24,502 & 4,313 \\
\hline Entries $^{b}$ & 35 & 5 & 3 & 5 \\
\hline Preference $^{c}$ & 64 & 4 & 5 & 2 \\
\hline \multicolumn{5}{|c|}{$\begin{array}{l}a \text { Average, median, and total number of views for each category as of } \\
\text { May } 12,2020 .{ }^{b} \text { Number of entries for each category on the TikTok } \\
\text { platform. "Student responses }(N=75) \text { to the multiple-choice survey } \\
\text { question "Which type of video did you enjoy watching most?" }\end{array}$} \\
\hline
\end{tabular}

There are several factors that may contribute to this preference for anthropomorphized videos for both the surveyed students and broader online audience. First, behavioral studies have widely established a positive correlation between social media engagement and visual content featuring human faces over inanimate objects. ${ }^{25,26}$ Second, performative anthropomorphosis has become increasingly popular in viral social media videos that communicate biological and biochemical concepts. The anthropomorphized ChemClout videos follow the same general formula created by the new vanguard of science communicator who act out biological processes in entertaining fashion on TikTok. ${ }^{22}$ Some of these videos were shown to students on the first day of class, which may explain why more videos following this format were made compared to the other formats.

Previous studies have described the use of chemical anthropomorphism in YouTube videos ${ }^{6}$ and creative writing assignments ${ }^{27}$. However, the majority of reports have focused on showcasing research experiences, lab techniques, lab experiments, at-home experiments, explaining chemistry, and rationalizing everyday occurrences from a chemical perspective. $5,6,8,9,12,20,21$ Our findings suggest that chemical anthropomorphism is an effective format for communicating chemical concepts through social media videos on emerging platforms such as TikTok. 
Table 4. Student responses to Likert scale survey questions related to perceived educational impact.

\begin{tabular}{|c|c|c|c|c|c|}
\hline & $\begin{array}{r}\text { Strongly } \\
\text { Disagree } \\
(1)\end{array}$ & $\begin{array}{r}\text { Disagree } \\
(2)\end{array}$ & $\begin{array}{r}\text { Neutral } \\
\text { (3) }\end{array}$ & $\begin{array}{r}\text { Agree } \\
\text { (4) }\end{array}$ & $\begin{array}{r}\text { Strongly } \\
\text { Agree } \\
(5)\end{array}$ \\
\hline $\begin{array}{l}\text { a) Making ChemClout videos improved my } \\
\text { understanding of the course material. }{ }^{a}\end{array}$ & 2 & 3 & 18 & 26 & 26 \\
\hline $\begin{array}{l}\text { b) Watching ChemClout videos improved my } \\
\text { understanding of the course material. }{ }^{a}\end{array}$ & 3 & 2 & 12 & 32 & 26 \\
\hline $\begin{array}{r}\text { c) The activity made chemistry feel more } \\
\text { relatable. }{ }^{a}\end{array}$ & 1 & 0 & 7 & 28 & 38 \\
\hline $\begin{array}{l}\text { d) The videos helped me remember CHEM1B } \\
\text { concepts two months after the course was over. }{ }^{a}\end{array}$ & 3 & 1 & 14 & 31 & 26 \\
\hline $\begin{array}{l}\text { e) The ChemClout Challenge was a valuable } \\
\text { addition to my learning experience. }{ }^{a}\end{array}$ & 1 & 1 & 11 & 30 & 32 \\
\hline $\begin{array}{l}\text { f) Compared to the activities in your science } \\
\text { courses at UCR, how would you rate the } \\
\text { ChemClout Challenge? } b\end{array}$ & 1 & 0 & 2 & 20 & 52 \\
\hline
\end{tabular}

\section{EDUCATIONAL IMPACT ON GENERAL CHEMISTRY STUDENTS}

Students completing the voluntary survey indicated that the ChemClout Challenge positively influenced

their attitude toward chemistry, understanding of concepts, and retention of information (Table 4). Students felt that both making videos and watching videos improved their understanding of chemical concepts. Overall, students felt that watching the videos had a slighter greater impact on their understanding of the course material than creating the videos. While video creation is an active process, each student group created only one video. 71 publicly accessible videos were produced in total, and many students watched the videos made by their peers outside their project group. Students in the course watched and left supportive comments on each other's videos. The breadth of concepts and diversity of explanations covered in these 71 videos may rationalize the greater perceived sense of learning by watching.

One of the difficulties that students face in learning chemistry is that the course content may come across as abstract and unrelatable. Encouragingly, 88\% of surveyed students agreed or strongly agreed that the activity made chemistry feel more relatable, with only 1 out of 75 students disagreeing. These findings are in line with reports that anthropomorphosis in science makes scientific concepts more 
relatable. ${ }^{28}$ Students generally felt the activity was a valuable learning experience. $76 \%$ of respondents noted that the videos helped them remember chemical concepts from CHEM1B two months after the conclusion of the course. As general chemistry is a foundational course for majors across science and engineering, such long-term retention of basic chemical principles is anticipated to help students in their future coursework. $96 \%$ of students rated the ChemClout Challenge as a "4" or " 5 " on a scale of 15 compared to activities in their other science courses at UC Riverside, suggesting the students generally feel that making science-themed social media videos was a worthwhile use of their time.

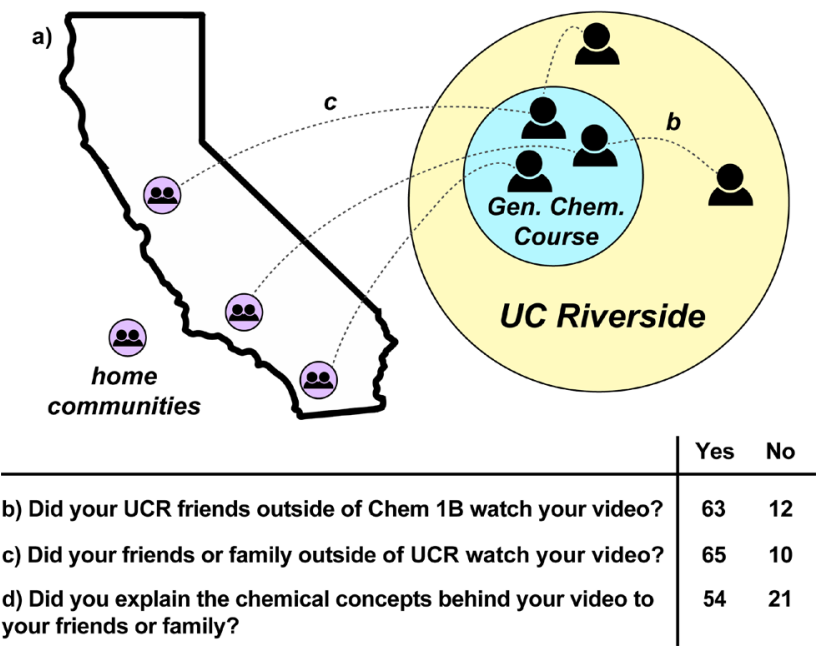

Figure 3. Students used their videos to engage their local and home communities in general chemistry topics. (a) A schematic depicting engagement at the local and regional level through videos permeating student social networks or students explaining the concepts behind their videos. (b-d) Survey responses to evaluate student-initiated outreach $(\mathrm{N}=75)$.

\section{REGIONAL AND GLOBAL PUBLIC ENGAGEMENT}

An additional motivation for this program was for students to engage their home communities in chemistry-oriented outreach through the channels of social media (Figure 3a). UCR enrolls more Pell Grant-receiving students than any other university in America. ${ }^{29}$ Many UC Riverside students come from low socioeconomic environments where there are greater barriers to participation in science and entry into STEM career paths. ${ }^{30-32}$ Students who elected to post videos to their own accounts rather

than a single course account facilitated chemical science outreach to their hometowns. By tapping into the students' social networks across California and beyond, these videos could potentially serve as beacons to draw students from these communities toward science and highlight both chemistry and higher education as subjects of interest. The activity was successful in this regard: $87 \%$ of students reported that their friends at UC Riverside outside of the class watched the videos, whereas $84 \%$ of 
students reported that their friends and family members outside of UC Riverside watched their videos. $72 \%$ of students reported personally explaining the chemical concepts behind their video to their friends and family who watched the videos (Figure $3 \mathbf{b}-\mathbf{d})$.

From a broad public engagement perspective, impact was assessed by considering view counts and comments left on the videos on the TikTok app. On TikTok, the ChemClout videos received nearly 1.1 million total views, amongst the highest viewership numbers reported for activities that integrate chemistry with social media. On the most popular videos, comments were left in several languages including Polish, Russian, Spanish, French, and German, demonstrating the global reach of the viral videos. Google Translations of the non-English comments indicated that students across languages and countries appreciated and shared these videos with their peers.

\section{COMPATIBILITY WITH DISTANCE LEARNING}

Social media as a learning tool has found particular utility in situations where in-person instruction is limited or unavailable, as is currently the case due to the COVID-19 crisis. In response, chemical educators around the globe have implemented apps such as Instagram, WeChat, Facebook, and Discord to digitally connect with their students. ${ }^{33-35}$ The ChemClout Challenge may provide a framework for connecting student classmates during this remote period. Students are capable of creating these videos at home independently, with the help of family members, or potentially splicing videos together from multiple students as a group project. From an outreach perspective, students across America are especially primed for social media consumption during the COVID-19 pandemic. A recent survey of 609 participants aged 18-25 indicated that nearly all users increased their social media intake over the pandemic period, with $68 \%$ of participants reporting increased usage by at least one hour. ${ }^{36}$ These data indicate particularly fertile conditions for public engagement in chemistry via social media videos. Furthermore, pre-existing experience with social media apps should be equitable across groups - a 2019 Pew Research Center study reported that students from underrepresented and well-represented groups in STEM engage in social media activity at similar rates. ${ }^{37}$

\section{CONCLUSION}

Our survey responses and viewership metrics support that student-created social media videos are effective vectors for student-centered learning and public engagement in chemical concepts. Students 
felt that the activity improved their understanding of the course material and contributed to their retention of general chemistry concepts two months after the course conclusion. Early indications point toward improved exam performance for students who participated in the ChemClout Challenge.

Further studies need to be conducted in order to conclusively evaluate pre- and post-activity performance.

With the emergence of social media apps and the introduction of students to smartphones at earlier ages, students are more attached to social media technology than ever before. ${ }^{38}$ The ChemClout Challenge, along with the other activities reported in the chemical education literature that integrate chemistry with social media, aspires to claim a space for chemistry in the daily social media consumption cycles of students and the wider population. We feel that a key component for accomplishing this objective is to give students the agency to create videos that they felt would find the widest appeal. It is often the students rather than the instructors that have the most refined sense for how to create videos and social media content that their peers will find compelling. Recent popular science videos on TikTok have anthropomorphized biochemical or biological concepts. Students in the course elected to similarly anthropomorphize chemistry and found this strategy to be effective for engaging online audiences in chemical concepts.

While the activity was deployed for a large introductory general chemistry course, the general methods from this study can be easily ported to other courses in chemistry, biochemistry, biology, and physics. The integration of scientific content with social media in classrooms across disciplines may empower students to teach their communities about science, particularly students who did not previously see themselves as being capable of engaging others in science.

\section{ASSOCIATED CONTENT}

The Supporting Information is available on the ACS Publications website at DOI:

10.1021/acs.jchemed.XXXXXXX.

Supplementary Note 1, Activity Syllabus. (DOCX) 


\section{AUTHOR INFORMATION}

*E-mail: timothys@ucr.edu

\section{Author Contributions}

${ }^{2}$ M.O.H. and N.Q.N. contributed equally to the work presented in this manuscript and are credited as co-first authors for this publication.

Notes

The authors declare no competing financial interest.

\section{ACKNOWLEDGMENTS}

We are deeply indebted to the students at UC Riverside who created these videos, participated in the activity, and completed the voluntary surveys that are discussed in this manuscript. We thank Jack Eichler (UC Riverside) for helpful discussions as well as Darrion Nguyen (Baylor College of Medicine) and Luis Campos (Columbia University) for inspiring this activity.

\section{REFERENCES}

1. Salim, S. How Much Time Do You Spend on Social Media? Research Says 142 Minutes per Day. https://www.digitalinformationworld.com/2019/01/how-much-time-do-people-spend-socialmedia-infographic.html (accessed Aug 25, 2020).

2. Greenhow, C. Youth, Learning, and Social Media. J. Educ. Comput. Res. 2011, 45 (2), 139-146. https://doi.org/10.2190/EC.45.2.a.

3. Rodriguez, J. E. Social Media Use in Higher Education: Key Areas to Consider for Educators. J. Online Learn. Teach. 2011, 7 (4), 539-550. https://doi.org/ISSN 1558-9528.

4. Jacobsen, W. C.; Forste, R. The Wired Generation: Academic and Social Outcomes of Electronic Media Use among University Students. Cyberpsychology, Behav. Soc. Netw. 2011, 14 (5), 275280. https://doi.org/10.1089/cyber.2010.0135.

5. Gallardo-Williams, M.; Morsch, L. A.; Paye, C.; Seery, M. K. Student-Generated Video in Chemistry Education. Chem. Educ. Res. Pract. 2020, 21 (2), 488-495. https://doi.org/10.1039/c9rp00182d.

6. Franz, A. K. Organic Chemistry YouTube Writing Assignment for Large Lecture Classes. J. Chem. Educ. 2012, 89 (4), 497-501. https://doi.org/10.1021/ed100589h.

7. Haran, B.; Poliakoff, M. How to Measure the Impact of Chemistry on the Small Screen. Nat. Chem. 2011, 3 (3), 180-182. https://doi.org/10.1038/nchem.990.

8. Smith, D. K. ITube, YouTube, WeTube: Social Media Videos in Chemistry Education and Outreach. J. Chem. Educ. 2014, 91 (10), 1594-1599. https://doi.org/10.1021/ed400715s.

9. Ranga, J. S. Customized Videos on a YouTube Channel: A beyond the Classroom Teaching and Learning Platform for General Chemistry Courses. J. Chem. Educ. 2017, 94 (7), 867-872. https://doi.org/10.1021/acs.jchemed.6b00774. 
10. Benedict, L.; Pence, H. E. Teaching Chemistry Using Student-Created Videos and Photo Blogs Accessed with Smartphones and Two-Dimensional Barcodes. J. Chem. Educ. 2012, 89 (4), 492496. https://doi.org/10.1021/ed2005399.

11. Seethaler, S. Organic Chemistry for the YouTube GenerationOrganic Chemistry for the YouTube Generation. https://ucsdnews.ucsd.edu/archive/newsrel/science/12-07sorgovideoSS-.asp (accessed Aug 24, 2020).

12. Lichter, J. Using YouTube as a Platform for Teaching and Learning Solubility Rules. J. Chem. Educ. 2012, 89 (9), 1133-1137. https://doi.org/10.1021/ed200531j.

13. Turkoguz, S. Learn to Teach Chemistry Using Visual Media Tools. Chem. Educ. Res. Pract. 2012, 13 (4), 401-409. https://doi.org/10.1039/c2rp20046e.

14. Jordan, J. T.; Box, M. C.; Eguren, K. E.; Parker, T. A.; Saraldi-Gallardo, V. M.; Wolfe, M. I.; Gallardo-Williams, M. T. Effectiveness of Student-Generated Video as a Teaching Tool for an Instrumental Technique in the Organic Chemistry Laboratory. J. Chem. Educ. 2016, 93 (1), 141-145. https://doi.org/10.1021/acs.jchemed.5b00354.

15. Wright, B. A Magical Reaction: Mix Chemistry, YouTube and a Special Teacher. https://newsroom.ucla.edu/stories/a-magical-reaction-mix-chemistry-271699 (accessed Aug 24, 2020).

16. Lerner, S. Orgo Music Videos Bring out the Best in Us. https:/ /www.columbiaspectator.com/2013/12/09/orgo-music-videos-bring-out-best-us / (accessed Aug 24, 2020).

17. Korich, A. L. Harnessing a Mobile Social Media App to Reinforce Course Content. J. Chem. Educ. 2016, 93 (6), 1134-1136. https://doi.org/10.1021/acs.jchemed.5b00915.

18. Underwood, S. M.; Kararo, A. T. Using Memes in the Classroom as a Final Exam Review Activity. J. Chem. Educ. 2020, 97 (5), 1381-1386.

https://doi.org/10.1021/acs.jchemed.0c00068.

19. Geyer, A. M. Social Networking as a Platform for Role-Playing Scientific Case Studies. J. Chem. Educ. 2014, 91 (3), 364-367. https://doi.org/10.1021/ed400261m.

20. Hurst, G. A. Utilizing Snapchat to Facilitate Engagement with and Contextualization of Undergraduate Chemistry. J. Chem. Educ. 2018, 95 (10), 1875-1880.

https://doi.org/10.1021/acs.jchemed.8b00014.

21. Hayes, C.; Stott, K.; Lamb, K. J.; Hurst, G. A. "Making Every Second Count": Utilizing TikTok and Systems Thinking to Facilitate Scientific Public Engagement and Contextualization of Chemistry at Home. J. Chem. Educ. 2020, acs.jchemed.0c00511. https://doi.org/10.1021/acs.jchemed.0c00511.

22. Lemonick, S. Chemists Are Finding Their Place on TikTok. Chem. Eng. News 2020, 98 (8).

23. Gilbert, T. R.; Kirss, R. V.; Foster, N.; Bretz, S. L. Chemistry: An Atoms-Focused Approach, Second Edi.; W. W. Norton \& Company, Inc.: New York, NY, 2018.

24. Everything Brands Need to Know About TikTok in 2020. https://blog.hootsuite.com/what-istiktok/ (accessed Aug 20, 2020).

25. Bakhshi, S.; Shamma, D. A.; Gilbert, E. Faces Engage Us: Photos with Faces Attract More Likes 
and Comments on Instagram. Conf. Hum. Factors Comput. Syst. - Proc. 2014, 965-974. https://doi.org/10.1145/2556288.2557403.

26. Souza, F.; De Las Casas, D.; Flores, V.; Youn, S. B.; Cha, M.; Quercia, D.; Almeida, V. Dawn of the Selfie Era: The Whos, Wheres, and Hows of Selfies on Instagram. COSN 2015 - Proc. 2015 ACM Conf. Online Soc. Networks 2015, 221-231. https://doi.org/10.1145/2817946.2817948.

37. Pew Research Center. Social Media Fact Sheet. https://www.pewresearch.org/internet/factsheet/social-media/ (accessed Aug 21, 2020).

38. Ortiz-Ospina, E. The Rise of Social Media. https://ourworldindata.org/rise-of-social-media (accessed Aug 21, 2020). 